\title{
Commentary: Black or white: The false dichotomy argument inherent in comparing biventricular repair versus Fontan completion
}

\author{
Tara Karamlou, MD, MSc, and Hani K. Najm, MD, MSc
}

From the Division of Pediatric Cardiac Surgery, Heart Vascular Institute, Cleveland Clinic, Cleveland, Ohio.

Disclosures: Authors have nothing to disclose with regard to commercial support.

Received for publication May 27, 2019; accepted for publication May 29, 2019; available ahead of print July 10, 2019.

Address for reprints: Tara Karamlou, MD, MSc, Cleveland Clinic Children's Heart and Vascular Institute, 9500 Euclid Ave, M41-022A, Cleveland, OH 44195 (E-mail: karamlt@ccf.org).

J Thorac Cardiovasc Surg 2019;158:1168-70

$0022-5223 / \$ 36.00$

Copyright (c) 2019 by The American Association for Thoracic Surgery

https://doi.org/10.1016/j.jtcvs.2019.05.074

The logical fallacy of false dilemma is an argument that fails by limiting the options to two, when more than two options actually exist. Although it may seem that a dichotomous perspective is appropriate when comparing univentricular or biventricular strategies, given that a patient must have either a 1- or a 2-ventricle circulation, the contemporary treatment approach is realistically more nuanced and complex. It may not be too far afield therefore, at the risk of being overly philosophical, to suggest that the current article by Sun and colleagues ${ }^{1}$ in this issue of the Journal, "Biventricular Repair Versus Fontan Completion for Patients with D- or L-Transposition of the Great Arteries with Ventricular Septal Defect and Left Ventricular Outflow Tract Obstruction," may drift into this deductive trap. But we are getting ahead of ourselves.

This group ${ }^{1}$ from Australia, who are considered thought leaders in the study of Fontan outcomes, have investigated the midterm outcomes of 129 patients from Australia with D-transposition of the great arteries with ventricular septal defect and left ventricular outflow tract obstruction $(\mathrm{N}=85)$ or $\mathrm{L}$-transposition of the great arteries with ventricular septal defect and left ventricular outflow tract obstruction $(\mathrm{N}=44)$ and 2 functional ventricles who underwent primary surgical intervention between 1990 and 2015. Of these, 29 underwent Fontan completion, and 100 underwent biventricular repair. Overall transplant-free survival at 15 years was excellent at $90 \%$. Reintervention-free survival was comparably poor, however, with only $29 \%$ of patients escaping reintervention at 15 years. Cumulative timerelated outcomes, including functional status (as measured by New York Heart Association functional class), were essentially equivalent among both groups. When considered in isolation, however, "expected" reinterventions, such as conduit exchanges or fenestration closure, were more prevalent among the biventricular group than the Fontan group. Sun and colleagues ${ }^{1}$ conclude that intermediate outcomes for both pathways are thus similar and that the

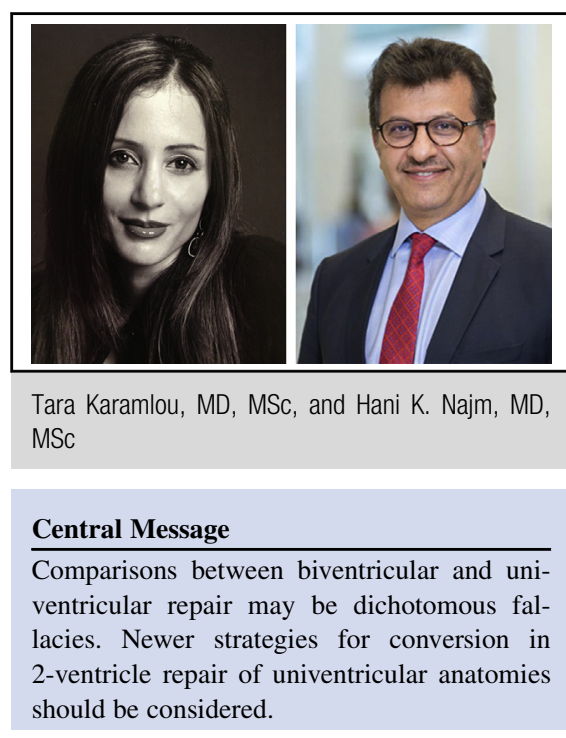

See Article page 1158 .

Fontan procedure is a viable option when anatomic riskfactors preclude biventricular repair. The critical concept to bear in mind is encapsulated by the term "preclude" but we will get back to that. The article is exceptionally well written, and the topic is timely.

The benefits of a biventricular circulation versus a univentricular circulation are often articulated, and at present, they may have increased resonance with growing appreciation of the long-term adverse, multiorgan system sequelae of Fontan physiology. Proponents of the use of a univentricular strategy among patients in whom the left ventricle is difficult to route to the aorta, such as those in the study of Sun and colleagues, ${ }^{1}$ point out that the durability of a univentricular repair is improved among Fontan recipients with 2 adequately sized ventricles. It is clear that chronic systemic venous hypertension inherent in the Fontan population leads to the development of multiple end-organ complications; however, these are variable in timing and often do not manifest for decades. The veracity of the latter argument about 2-ventricle univentricular outcomes being superior to 1-ventricle univentricular outcomes is much more opaque. Recent data from Marathe and coworkers, ${ }^{2}$ demonstrating that 15-year freedom from a composite end point of Fontan failure was equivalent among a propensity-matched group of 75 patients with Fontan circulations with 2 
adequate ventricles versus 604 patients with singleventricle Fontan circulations ( $79 \%$ vs $87 \%$ ), would suggest that perhaps a reconsideration is warranted.

Beyond the overarching concept of relative benefits of treatment approach (and whether one has a bias toward one viewpoint or the other), a major critique of the paper by Sun and colleagues ${ }^{1}$ is that the study inception is at time of complete "repair." The cohort outcomes are thus biased in favor of Fontan recipients, because they neglect important pre-Fontan attrition, which is estimated to be nearly $50 \%$ according to the 2015 data from the Congenital Heart Surgeons' Society. ${ }^{3}$ The results reported by Sun and colleagues, ${ }^{1}$ should therefore be viewed in the context of the larger group of patients with univentricular circulations who do not survive to Fontan completion. In this holistic way, one can understand what the cumulative risks of this pathway are for the actual patient. The other issues with the article center on the limited follow-up (median of 6.2 years), which may be too constrained to capture the variable timing of "Fontan failure," and the lack of data on exercise capacity and health-related quality of life. Although Sun and colleagues ${ }^{1}$ showed that isolated "expected" reinterventions were more prevalent in the biventricular group (which can certainly negatively affect quality of life), these results were heavily influenced by the only 4 patients to undergo the Senning-Nikaidoh procedure, who experienced a disproportionately high risk of reintervention. Given the very small number of patients, the lens of circumspection is advised. Further, it is known from other complex congenital diagnoses in which there are potential biventricular and univentricular strategies that a biventricular strategy may increase the rate of reintervention but may pay dividends in terms of exercise capacity or physical functioning assessed by dedicated quality-of-life instruments. In point of fact, the controversy regarding the relative merits of a biventricular circulation in those with borderline anatomy compared with a univentricular circulation persists mainly because of the lack of data comparing long-term exercise capacity and health-related quality of life among a cohort of patients eligible for either biventricular or univentricular repair. Karamlou and colleagues ${ }^{4}$ examined this question in a prospective cohort of patients with pulmonary atresia with intact ventricular septum and found that peak oxygen uptake at 15 years after initial repair was higher for those with larger indexed tricuspid valve $z$ score for all endstate groups, with an important interaction magnifying this effect within the biventricular group. Chronotropic function also tended to be better in the biventricular group, which could lead to enhanced response to physiologic stress (including exercise) and preserved ventricular function. Results of the Pediatric Heart Network Fontan 3 CrossSectional Evaluation ${ }^{5}$ corroborate the disappointing longterm outcomes for Fontan recipients, in which the steady decline in time-related survival was mirrored by decreasing exercise performance within nearly all investigated parameters, coupled with worsening functional status. It is probable that had Sun and colleagues ${ }^{1}$ used dedicated metrics for these critical components, a biventricular strategy might have fared better.

Let us now return to the editorial preamble, and the validity of the binary argument of biventricular repair versus Fontan completion for the population of patients with Dor L-transposition of the great arteries with ventricular septal defect and left ventricular outflow tract obstruction. Other than a Fontan or typical biventricular repair, are there alternative potential treatment possibilities that can be leveraged? We would argue, given recently presented data ${ }^{6}$ demonstrating the feasibility of the "ventricular switch" for 2-ventricle repair patients in patients with univentricular anatomy, that the notion of Sun and colleagues ${ }^{1}$ notion of "impossibility of biventricular conversion" is relative, and therefore that the dichotomous fallacy error is relevant. Although the concept of biventricular conversion among patients with hypoplasia of either the left or right-sided components is not new, our group used a paradigm that utilizes the morphologic left ventricle as the subpulmonary ventricle in a complex group of patients thought to be "unseptatable" because of the inability to route the pulmonary venous return to the aorta. This strategy can be extended to multiple anatomic configurations, including those described in the current report of Sun and colleagues. ${ }^{1}$ Clearly, we recognize that this is just one new approach that has yet to show long-term success. Given, however, the rapidly evolving imaging modalities, 3-dimensional reconstruction, and virtual surgery technology, the potential armamentarium available to drive innovative septation techniques is growing. In the interim, we should avoid devolving into the artificially constrained and increasingly irrelevant black-and-white perspective expressed by Andre Castaigne, "It is very simple. If I am wrong, they are right. Thus I should be doing the opposite of what I was doing, as that will be the right thing to do. I do not need to think about it. I do not need to introduce complexity where there is none." This approach, after all, leads only backward in time to where we have already been, rather than forward to the unknown possible.

\section{References}

1. Sun J, Brizard C, Winlaw D, Alphonso N, d'Udekem Y, Eastaugh L, et al Biventricular repair versus Fontan completion for patients with d- or 1-transposition of the great arteries with ventricular septal defect and left ventricular outflow tract obstruction. J Thorac Cardiovasc Surg. 2019;158:1158-67.e1.

2. Marathe SP, Zannino D, Shi WY, du Plessis K, Kehr J, Perumal G, et al. Two ventricles are not better than one in the Fontan circulation: equivalent late outcomes. Ann Thorac Surg. 2019;107:852-9.

3. Wilder TJ, McCrindle BW, Phillips AB, Blackstone EH, Rajeswaran J, Williams WG, et al. Survival and right ventricular performance for matched children after stage-1 Norwood: modified Blalock-Taussig shunt versus right-ventricle-to-pulmonary-artery conduit. J Thorac Cardiovasc Surg. 2015; $150: 1440-52$ 
4. Karamlou T, Poynter JA, Walters HL III, Rhodes J, Bondarenko I, Pasquali SK, et al. Long-term functional health status and exercise test variables for patients with pulmonary atresia with intact ventricular septum: a Congenital Heart Surgeons Society study. J Thorac Cardiovasc Surg. 2013;145:1018-27.e3.

5. Atz AM, Zak V, Mahony L, Uzark K, D'agincourt N, Goldberg DJ, et al; Pediatric Heart Network Investigators. Longitudinal outcomes of patients with single ventricle after the Fontan procedure. J Am Coll Cardiol. 2017;69: 2735-44.
6. Najm HK, Karamlou T, Ahmad M, Hasan S, Yaman M, Stewart R, Pettersson G Biventricular conversion in unseptatable hearts: the left ventricle as the subpulmonary ventricle in complex congenital heart disease as an alternative to single ventricle palliation. Presented at: American Association for Thoracic Surgery 99th Annual Meeting; May 4-7, 2019; Toronto, Ontario, Canada.

7. Castaigne A. "False dilemma" dispatches from the cultural wars. Available at: http://rationalwiki.org/wiki/User_talk:Castaigne\#Vandal_bin. Accessed January 24, 2019. 